\title{
Critical Gap in Roundabouts - A Short Comparison of Estimation Methods
}

\author{
Haitham Al Hasanat ${ }^{1 *}$, Gábor Schuchmann \\ ${ }^{1}$ Department of Highway and Railway Engineering, Faculty of Civil Engineering, Budapest University of Technology and \\ Economics, H-1111 Budapest, Műegyetem rkp. 3., Hungary \\ * Corresponding author, e-mail: haitham.alhasanat@gmail.com
}

Received: 24 May 2021, Accepted: 14 February 2022, Published online: 03 March 2022

\begin{abstract}
Gap-acceptance method is one of the classical methods used to analyze the capacity of roundabouts. Critical gap has a privileged role in this approach. Different driver behavior and local rules of traffic have key role in implementing gap-acceptance method into the local standard for capacity calculation in each country. Therefore, a reliable method for estimation of critical gap at a certain location can be of great importance. This paper presents an experimental investigation and analysis on whether it is possible to find differences between estimating critical gap using video-based gap acceptance data of roundabouts in Hungary. Three single lane roundabouts of different size were recorded for hours in different locations in Budapest and Érd to assess gap acceptance data. Three different methods or models were used to estimate critical gap and no significant differences were found between their results.
\end{abstract}

\section{Keywords}

critical gap, roundabout, estimation, gap acceptance

\section{Introduction}

Roundabouts are very popular in Europe and worldwide as they represent a type of intersection without signals due to the circular geometric layout. The United Kingdom developed the modern roundabout to solve the problems aligned with these traffic circles. In 1966, the Give-way rule was presented and adopted at all existing roundabouts, which required the entering vehicles to either give way or yield to circulating traffic. This rule restricted vehicles from entering the roundabout until there were sufficient gaps in circulating traffic (Robinson, 2000).

Two consecutive vehicles circulating the carriageway (see Fig. 1) generate these gaps. The distribution of the size of these gaps is an influential parameter that affects the capacity of roundabouts, because the entering vehicle either accepts and merges into the gap in the circulating traffic or rejects it and waits for a sufficient gap to accept (see Fig. 1).

While gaps can be observed on site, critical gap itself can only be calculated from the observation of accepted and rejected gaps. As such, the critical gap depends a lot on local conditions like geometric layout, driver behaviour, and traffic conditions (Tian et al., 2000).
There are different methods available for estimating the critical gap (Raff, 1950; Ashworth, 1970; Troutbeck, 1992; Brilon et al., 1999). In this paper, authors compare three of these methods on real gap acceptance data measured using video recordings of 3 different single-lane roundabouts to find the differences of these estimation methods on the real critical gap.

\section{Methodology}

Three single-lane four-leg roundabouts of the same traffic situation were selected in Budapest and in Érd as shown in Fig. 2.

Field data was collected using a video camera recorder on a $4 \mathrm{~m}$ long pole placed at a specific location in each roundabout to view the whole roundabout and all entry legs are visible. and the specification of the used camera described in Table 1.

The video recording was carried out on two different occasions, in the morning peak hour and evening peak hour for a specific time for each roundabout, as shown in Table 2 below. 


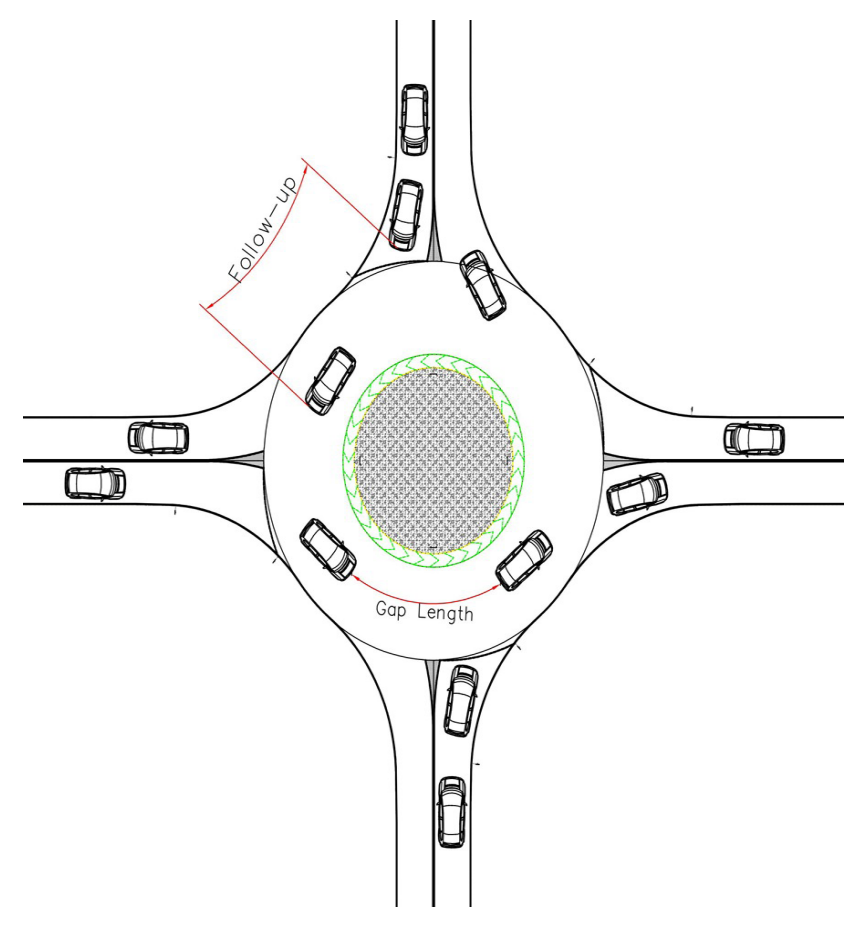

Fig. 1 Gap length and follow-up headway

AVS video converter Software was used to add a timestamp in milliseconds on each video for analysis purposes. In addition to the above, VLC Player software was used for video playing because it is flexible and easy to use Fig. 3.
Table 1 Camera specification

\begin{tabular}{lc}
\hline Specifications & \\
\hline Manufacture & SJCAM \\
Model & SJ4000 WIFI ACTION CAMERA \\
Sensor & $12.0 \mathrm{MP}$ CMOS sensor \\
Lens & 170 Degree HD wide-angle Lens \\
& $1080 \mathrm{P}(1920 * 1080)$ 30FPS \\
Resolution of videos & $720 \mathrm{P}(1280 * 720) 60 \mathrm{FPS}$ \\
recorded & $720 \mathrm{P}(1280 * 720) 30 \mathrm{FPS}$ \\
& WVGA $(640 * 480) 60 \mathrm{FPS}$ \\
\hline
\end{tabular}

Table 2 The locations of roundabouts, date and legth of recording

\begin{tabular}{lcccc}
\hline City & $\begin{array}{c}\text { Roundabout } \\
\text { location }\end{array}$ & $\begin{array}{c}\text { \# of } \\
\text { lanes }\end{array}$ & Date & $\begin{array}{c}\text { Length of } \\
\text { video }\end{array}$ \\
\hline \multirow{2}{*}{ Budapest } & Pasaréti tér & 1 & 19-Oct-20 & $4 \mathrm{~h}$ \\
Pusztaszeri & körönd & 1 & 09-Oct-20 & $4 \mathrm{~h}: 15 \mathrm{~m}$ \\
Érd & Érd-alsó & 1 & 17-Nov-20 & $2 \mathrm{~h}$ \\
\hline
\end{tabular}

Headway data were analyzed manually by analyzing each leg of each roundabout separately and recording each rejection or acceptance into an excel sheet then different methods were adopted to find the critical gap.

The collected data consisted of accepted and rejected gaps.

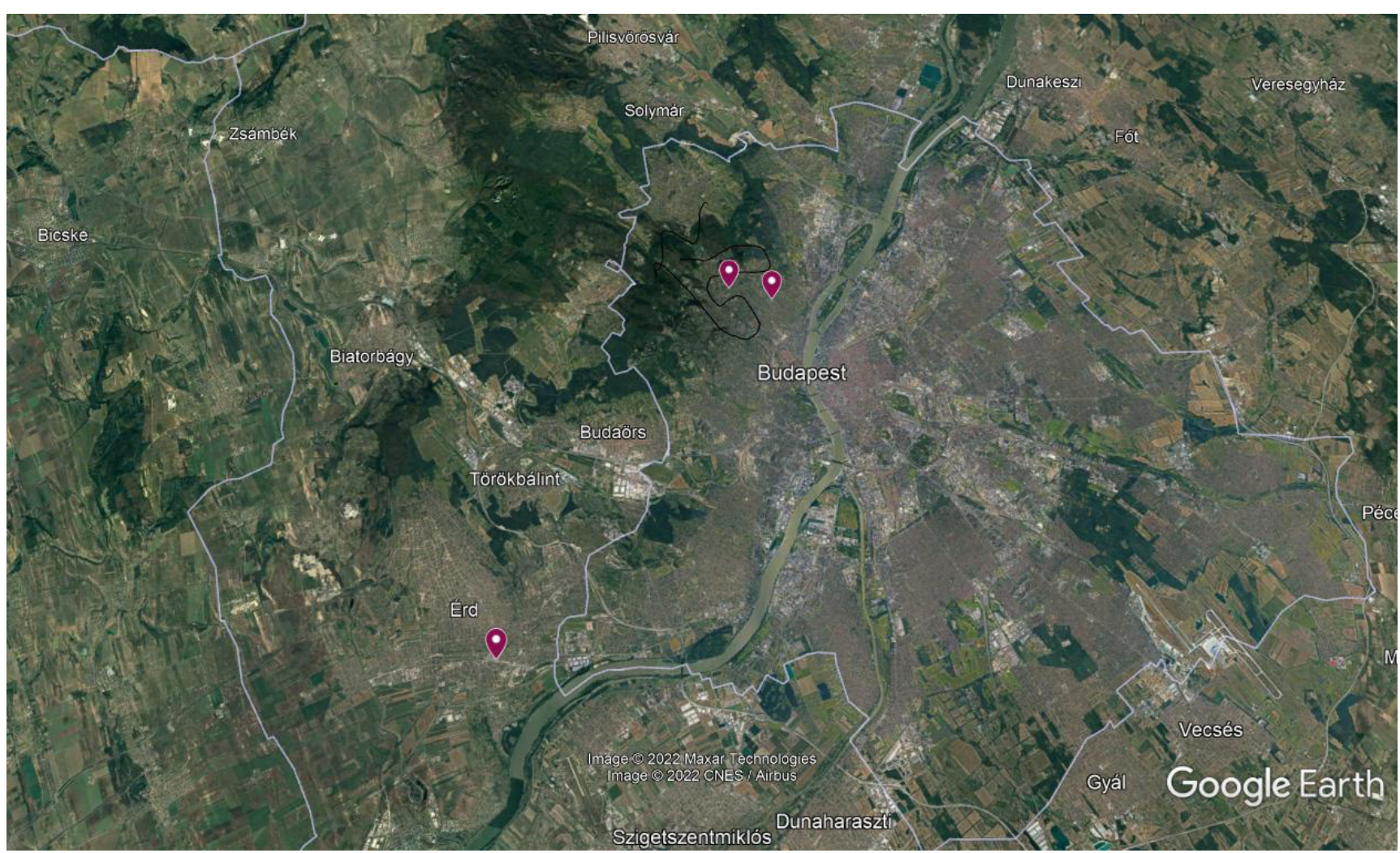

Fig. 2 Locations of the selected roundabouts 


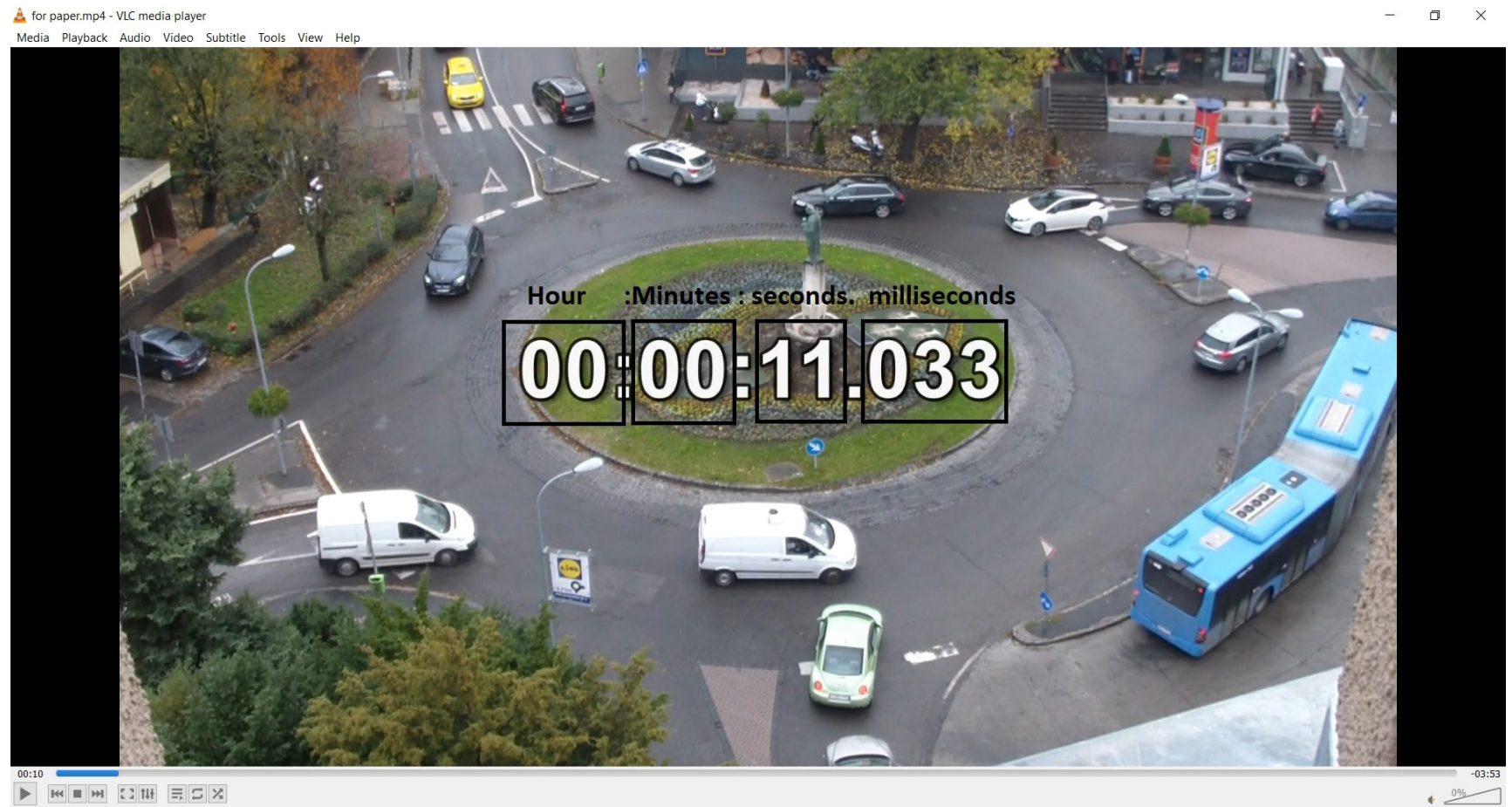

Fig. 3 AVS video converter added timestamp and VLC player

\section{Analysis}

Evaluation of the extracted data was carried out using three different methods, which were then compared with each other.

\subsection{Raff's method}

One of the popular methods used in estimating critical gap is Raff's method. It was introduced by Raff (1950) in the late 40 's, this method gained popularity due to the simplicity of implementations. and it introduced a macroscopic model for the estimation of critical gap. In this method both rejected and accepted gaps are tabulated in groups of intervals, then the percentage or probability of the rejected $1-F_{r}(t)$ and accepted gaps $F_{a}(t)$ of each group is calculated and plotted into graph, the intersection point of rejected gap graph and accepted gap at the graph is the critical gap of the extracted data as shown in the graphs. According to $\mathrm{Wu}$ (2012) the point of intercept doesn't correspond to the average of the critical gap distribution but to it's median.

\subsection{Wu's model}

Wu's model (Wu, 2012) is based on the macroscopic probability equilibrium of the rejected and accepted headways. This model has a solid theoretical background and gives a robust result, and it does not need any assumptions such as consistency or homogeneity of drivers, or predefined distribution function of the critical gaps as well as the limitation that rejected gap must be smaller than an accepted gap is not more necessary. The calculation procedure of the model is simple, and it needs no iteration and can be easily implemented into EXCEL spreadsheet.

The steps of estimating critical gaps as explained by $\mathrm{Wu}(2012)$ are as follows:

1. insert all measured and relevant (according to whether all or only the maximum rejected gaps with corresponding accepted gaps larger than the rejected gaps are taken into account) gaps $t$ in the major stream into the column 1 of the spreadsheet;

2. mark the accepted gaps with " $a$ " and the rejected gaps with " $r$ " in column 2 of the spreadsheet respectively;

3. sort all gaps (together with their marks " $a$ " and " $r$ ") in an ascending order;

4. calculate the accumulate frequencies of the rejected gaps, $n_{r j}$, in column 3 of the spreadsheet (that is: for a given row $j$, if mark $=" r$ " then $n_{r j}=n_{r j}+1$ else $n_{r j}=n_{r j}$, with $n_{r 0}=0$ );

5. calculate the accumulate frequencies of the accepted gaps, $n_{a j}$, in column 4 of the spreadsheet (that is: for a given row $j$, if mark $=" a$ " then $n_{a j}=n_{a j}+1$ else $n_{a j}=n_{a j}$, with $n_{a 0}=0$ );

6. calculate the PDF of the rejected gaps, $F_{j}(r)$, in column 5 of the spreadsheet (that is: for a given row $j$, $F_{j}(r)=n_{r j} / n_{\max }$ with $n_{\max }=$ number of gaps); 
7. calculate the PDF of the accepted gaps, $F_{a}\left(t_{j}\right)$, in column 6 of the spreadsheet (that is: for a given raw $j$, $F_{a}\left(t_{j}\right)=n_{a j} / n_{\max }$ with $n_{\max }=$ number of gaps;

8. calculate (according to equation (6)) the PDF of the estimated critical gaps, $F_{t c}\left(t_{j}\right)$, in column 7 of the spreadsheet (that is: for a given raw $j, F_{a}\left(t_{j}\right)=n_{a j} / n_{\max }$ with $n_{\max }=$ number of gaps);

9. calculate the frequencies of the estimated critical gaps, $p_{t c}\left(t_{j}\right)$, between the raw $j$ and $j-1$ in column 8 of the spreadsheet (that is: $p_{t c}\left(t_{j}\right)=F_{t c}\left(t_{j}\right)-F_{t c}\left(t_{j}-1\right)$;

10. calculate the class mean, $t_{d, j}$, between the raw $j$ and $j-1$ in column 9 of the spreadsheet (that is: $t_{d, j}=\left(t_{j}+t_{j-1} / 2\right)$

11. calculate the mean value and the variance of the estimated critical gaps (that is: $\left(t_{c, \text { mean }}=\operatorname{sum}\left[p_{t c}\left(t_{j}\right) \cdot t_{d, j}\right]\right.$ and $\left.\sigma^{2}=\operatorname{sum}\left[p_{t c}\left(t_{j}\right) \cdot t_{d, j}{ }^{2}\right]-\left(\operatorname{sum}\left[p_{t c}\left(t_{j}\right) \cdot t_{d, j}\right]\right)^{2}\right)$.

\subsection{Ashworth's method}

Ashworth stated that critical gap can be estimated from both the mean and standard deviation of observed accepted gaps by using the Eq. (1) (Ashworth, 1970).

$t_{c}=\mu_{a}-p^{*} \sigma_{a}^{2}$,

where:

- $p=$ circulating traffic, in vehicles per second;

- $\mu_{a}=$ mean of the accepted gaps, in seconds;

- $\sigma_{a}^{2}=$ std deviation of accepted gaps, in second ${ }^{2}$.

\section{Results}

\subsection{Location: Pasaréti tér, Budapest}

After implementing Raff's method as shown in the Fig. 4 below, the critical Gap was estimated, and the critical gap $t_{c}^{r}=2.84 \mathrm{~s}$.

Wu's model of critical gap estimation (using the same spreadsheet for the same location) can be seen in the Fig. 5, it gives a value for critical gap $t_{c}{ }^{w}=2.7 \mathrm{~s}$

Ashworth's method, on the other hand gave a critical value of $t_{c}^{a}=3.49 \mathrm{~s}$ see Table 3 .

Table 4 shows a comparison between the 3 methods used in estimation, where the base method of comparison is Raff's method.

\subsection{Location: Érd-alsó, Érd}

Using Raff's method, critical gap estimation resulted $t_{c}^{r}=2.98 \mathrm{~s}$ as shown in Fig. 6.

Similarly, Wu's model at this location gave a critical gap $t_{c}{ }^{w}=2.83 \mathrm{~s}$ as shown in Fig. 7

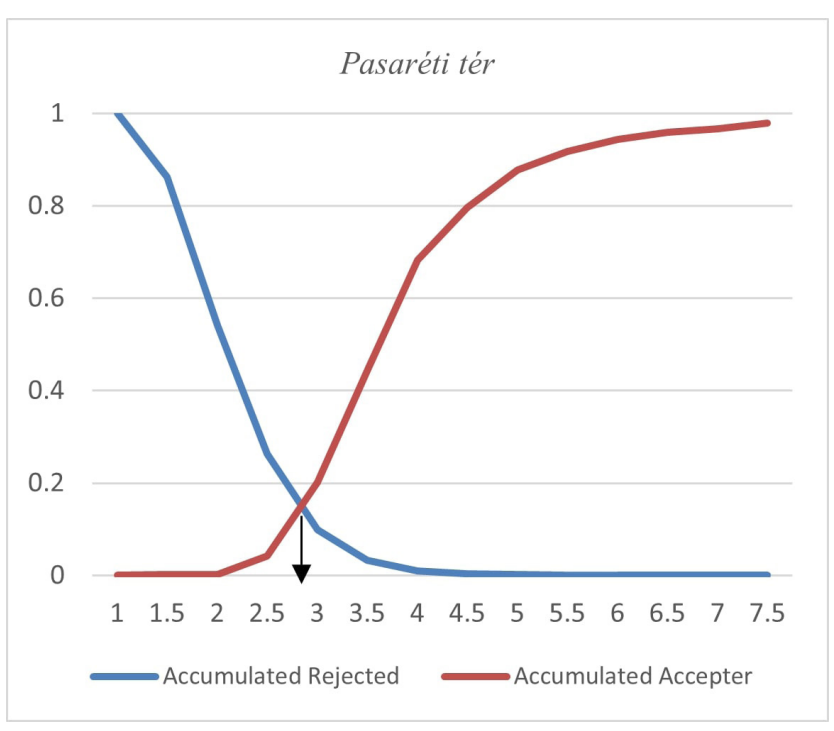

Fig. 4 Raff's method results for Pasaréti tér

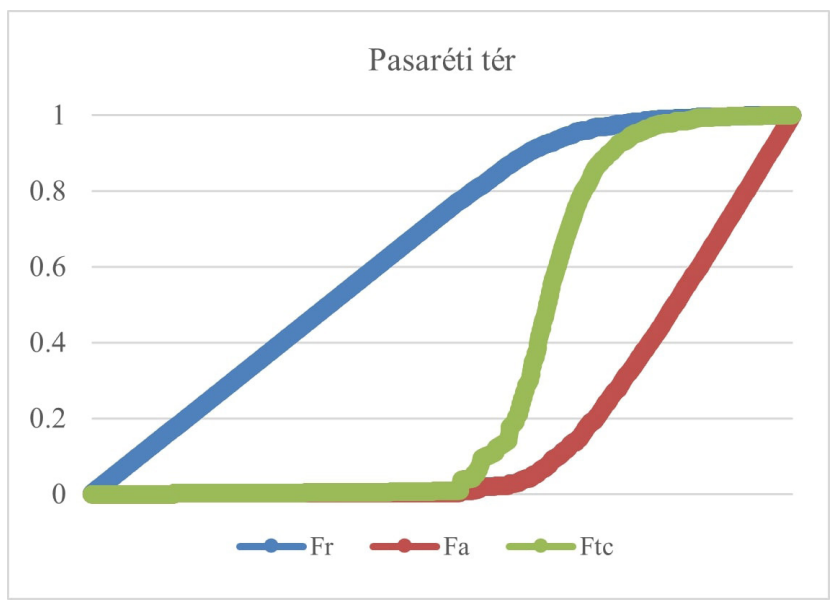

Fig. 5 Wu's model results for Pasaréti tér

Table 3 Ashworth's method for Pasaréti tér

\begin{tabular}{lcccc}
\hline Location & $P, \mathrm{sec}$ & $\mu_{a}, \mathrm{sec}$ & $\sigma_{a}^{2}, \mathrm{sec}^{2}$ & $t_{c}, \mathrm{sec}$ \\
\hline Pasaréti tér & $0.23 \mathrm{pcu} / \mathrm{sec}$ & 3.92 & 1.367 & $3.49 \mathrm{~s}$ \\
\hline
\end{tabular}

Table 4 Comparison of different methods for Pasaréti tér

\begin{tabular}{|c|c|c|}
\hline \multicolumn{3}{|c|}{ Critical gap at Pasaréti tér [s] } \\
\hline Raff's method & Wu's model & Ashworth's method \\
\hline \multirow[t]{2}{*}{2.84} & 2.7 & 3.49 \\
\hline & $-5.19 \% \quad+18.62 \%$ & \\
\hline
\end{tabular}

Ashworth's method in the same roundabout gave a critical value of $t_{c}{ }^{a}=3.49 \mathrm{~s}$ see Table 5 .

Table 6 shows a comparison between the 3 methods used in estimation, where the base method of comparison is Raff's method. 


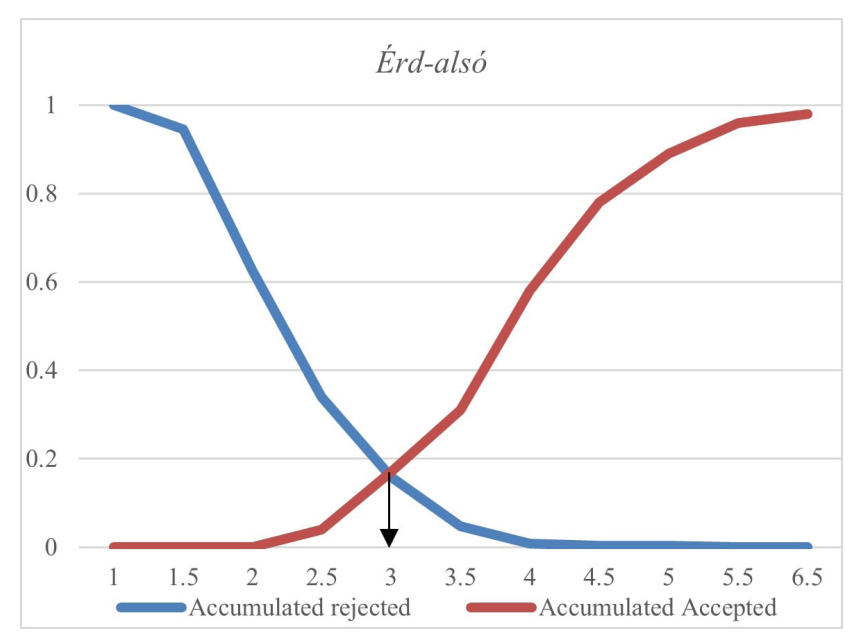

Fig. 6 Raff's results of Érd-alsó

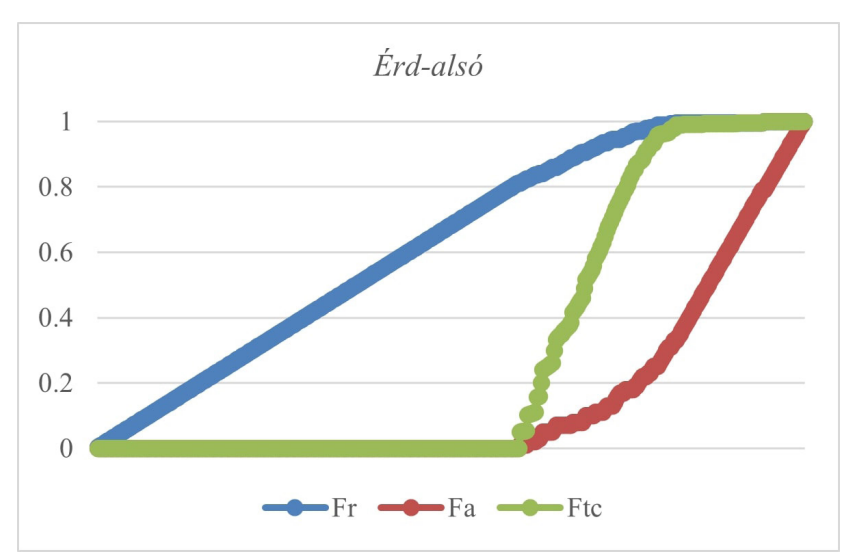

Fig. 7 Wu's model results of Érd-alsó

Table 5 Ashworth's method results for Érd-alsó

\begin{tabular}{lcccc}
\hline Location & $P, \mathrm{sec}$ & $\mu_{a}, \mathrm{sec}$ & $\sigma_{a}^{2}, \mathrm{sec}^{2}$ & $t_{c}, \mathrm{sec}$ \\
\hline Érd-alsó & $0.362 \mathrm{pcu} / \mathrm{sec}$ & 3.98 & 1.039 & 3.59 \\
\hline
\end{tabular}

Table 6 Comparison of different methods for Érd-alsó

\begin{tabular}{|c|c|c|c|}
\hline \multicolumn{4}{|c|}{ Critical gap at Érd-alsó [s] } \\
\hline Raff's method & Wu's & lodel & Ashworth's method \\
\hline \multirow[t]{2}{*}{2.98} & & & 3.59 \\
\hline & $-5.3 \%$ & $+17.0 \%$ & \\
\hline
\end{tabular}

\subsection{Location: Pusztaszeri körönd, Budapest}

Starting with Raff's method again, critical gap estimation resulted $t_{c}^{r}=2.76 \mathrm{~s}$ as shown in Fig. 8.

Wu's model of critical gap estimation (using the same spreadsheet for the same location) can be seen in Fig. 9, it gives a value for critical gap $t_{c}{ }^{w}=2.61 \mathrm{~s}$.

Finally, following Ashworth's method in this case as well, a critical value of $t_{c}^{a}=3.30 \mathrm{~s}$ was calculated in Table 7 .

Table 8 shows the comparison between our 3 methods

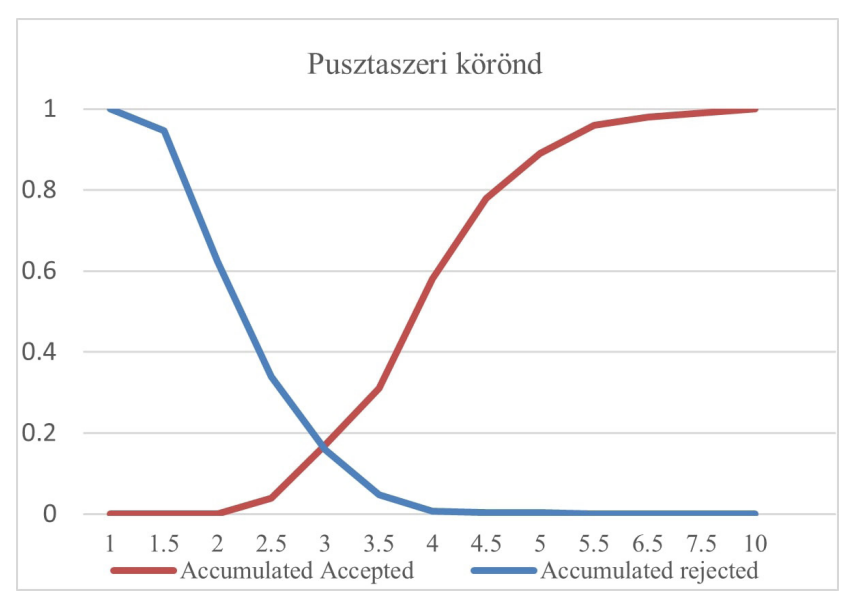

Fig. 8 Raff's method results of Pusztaszeri körönd

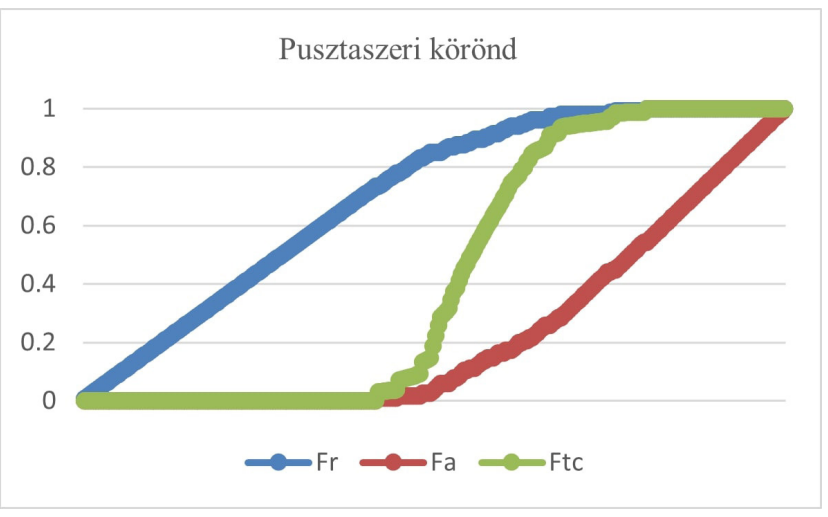

Fig. 9 Wu's model results of Pusztaszeri körönd

Table 7 Ashworth's method results for Pusztaszeri körönd

\begin{tabular}{lcccc}
\hline Location & $P, \mathrm{sec}$ & $\mu_{a}, \mathrm{sec}$ & $\sigma_{a}^{2}, \mathrm{sec}^{2}$ & $t_{c}, \mathrm{sec}$ \\
\hline Pusztaszeri körönd & $0.295 \mathrm{pcu} / \mathrm{sec}$ & 4.25 & 1.786 & $3.3 \mathrm{~s}$ \\
\hline
\end{tabular}

Table 8 Comparison of different methods for Pusztaszeri körönd

\begin{tabular}{ccc}
\hline \multicolumn{3}{c}{ Critical gap at Pusztaszeri körönd [s] } \\
\hline Raff's method & Wu's model & Ashworth's method \\
\hline 2.76 & 2.61 & 3.30 \\
& $-5.75 \%$ & $+16.36 \%$ \\
\hline
\end{tabular}

used at location Pusztaszeri körönd, where the base method of comparison is Raff's method.

\section{Conclusions, next steps}

After investigating the real values of critical gap, measured, and calculated on 3 different roundabouts applying three different methods, we can state that the difference between the results expressed always in the percentage of the result coming from Raff's method tend to be quite similar. 
It means that for further investigations on critical gap in roundabouts, theoretically any of them can be used.

Our suggestion for the similar processing of gaps based on video recordings, Raff's method should be used because

\section{References}

Ashworth, R. (1970) "The Analysis and Interpretation of Gap Acceptance Data", Transportation Science, 4(3), pp. 270-280.

https://doi.org/10.1287/trsc.4.3.270

Brilon, W., Koenig, R., Troutbeck, R. J. (1999) "Useful estimation procedures for critical gaps", Transportation Research Part A: Policy and Practice, 33(3-4), pp. 161-186.

https://doi.org/10.1016/S0965-8564(98)00048-2

Raff, M. S. (1950) "A Volume Warrant For Urban Stop Signs", The ENO Foundation for Highway Traffic Control, Saugatuck, CT, USA.

Robinson, B. W. (2000) "Roundabouts: An Informational Guide", U.S. Department of Transportation: Federal Highway Administration, Portland, OR, USA, Rep. FHWA-RD-00-067. of its striking simplicity (unlike Wu's steps), robustness and integrative nature considering all gaps including rejected ones (unlike Ashworth's method).

Tian, Z. Z.,Troutbeck, R., Kyte, M.. Brilon, W., Vandehey, M., Kittelson, W., Robinson, B. (2000) "A Further Investigation on Critical Gap and Follow-Up Time", In: Transportation Research Circular E-C018: 4th International Symposium on Highway Capacity, Washington, DC, USA, pp. 397-408.

Troutbeck, R. J. (1992) "Estimating the Critical Acceptance Gap from Traffic Movements", Physical Infrastructure Center, Queensland University of Technology, Brisbane, Australia, Rep. 92-5.

Wu, N. (2012) "Equilibrium of Probabilities for Estimating Distribution Function of Critical Gaps at Unsignalized Intersections", Transportation Research Record: Journal of the Transportation Research Board, 2286(1), pp. 49-55. https://doi.org/10.3141/2286-06 